\title{
Monitoring the Effects of Antagonists on Protein-Protein Interactions with NMR Spectroscopy
}

Loyola D'Silva, Przemyslaw Ozdowy, Marcin Krajewski, Ulli Rothweiler, Mahavir Singh and

Tad A. Holak*

Max Planck Institut für Biochemie, D-82152 Martinsried, Germany

E-mail: holak@biochem.mpg.de

\section{Supporting Information}




\section{Supporting Discussion: Using NMR to understand the extent of protein folding.}

The extent of folding in our various protein constructs was checked by $1 \mathrm{D}$ proton and $2 \mathrm{D}$ proton- ${ }^{15} \mathrm{~N}$ nitrogen NMR spectra (Rehm et al., 2002). Inspection of such spectra yields semi-quantitative information on folding in partially structured proteins or their domains (Wüthrich, 1986). For example, the appearance of intensities at proton chemical shifts near $\sim 8.3 \mathrm{ppm}$ is an indicator for a disordered protein, as this is a region characteristic of backbone amides in random coil configuration (Wüthrich, 1986). On the other hand large signal dispersion beyond $8.3 \mathrm{ppm}$ proves a protein to be folded. Due to the different chemical environment and thus the varying shielding effects the resonances of the single protons will be distributed over a wide range of frequencies.

Rehm, T., Huber, R. \& Holak, T.A. Application of NMR in structural proteomics: screening for proteins amenable to structural analysis. Structure 10, 1613-1618 (2002).

Wüthrich, K. NMR of Proteins and Nucleic Acids, Wiley, New York, 1986. 

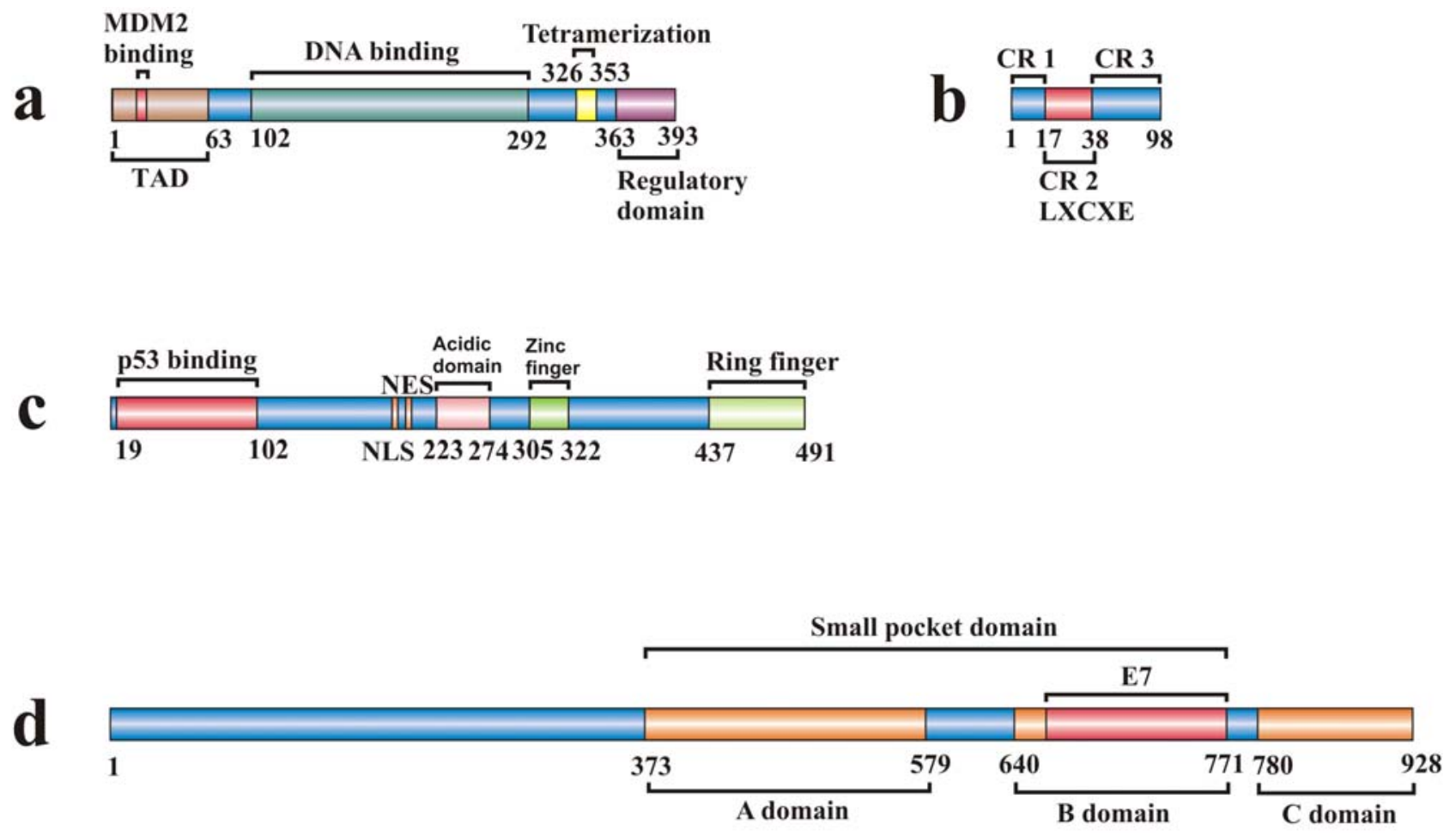

Supporting Figure 1. Schematic representations of the full-length proteins (a) p53, (b) HPV16 E7, (c) MDM2, and (d) pRb. 
Isothermal Titration Calorimetry. Binding of p53(1-312) to MDM2(1-118) was measured by isothermal titration calorimetry using a VP-ITC MicroCalorimeter (MicroCal, Northampton, MA). Proteins were used at concentration of $0.2-0.33 \mathrm{mM}$ in phosphate buffer $(150 \mathrm{mM} \mathrm{NaCl}, 50 \mathrm{mM}$ $\mathrm{KH}_{2} \mathrm{PO}$, $50 \mathrm{mM} \mathrm{Na} \mathrm{HPO}_{4}, 1 \mathrm{mM}$ 2-thioethanol, 2.0\% DMSO, pH 7.4) and titrated from a $300 \mu \mathrm{l}$ syringe into a sample chamber holding $1.43 \mathrm{ml}$ of $0.02-0.03 \mathrm{mM}$ respective binding partner. All solutions were degassed prior to measurements. At the equilibrium temperature of $20^{\circ} \mathrm{C}$, protein solutions (MDM2) were titrated into the sample chamber (p53) by 50 injections of $5 \mu$ each, lasting 10 $\mathrm{s}$ with $400 \mathrm{~s}$ intervals between injections. Heat generated by protein dilution was determined in separate experiments by injecting protein solution into phosphate buffer filled sample chamber. All data were corrected for the heat of protein dilution. Data were fitted using $\chi^{2}$ minimization on a model assuming a single set of sites to calculate the binding affinity $\mathrm{K}_{\mathrm{D}}$. All steps of the data analysis were performed using ORIGIN(V5.0) software provided by the manufacturer.

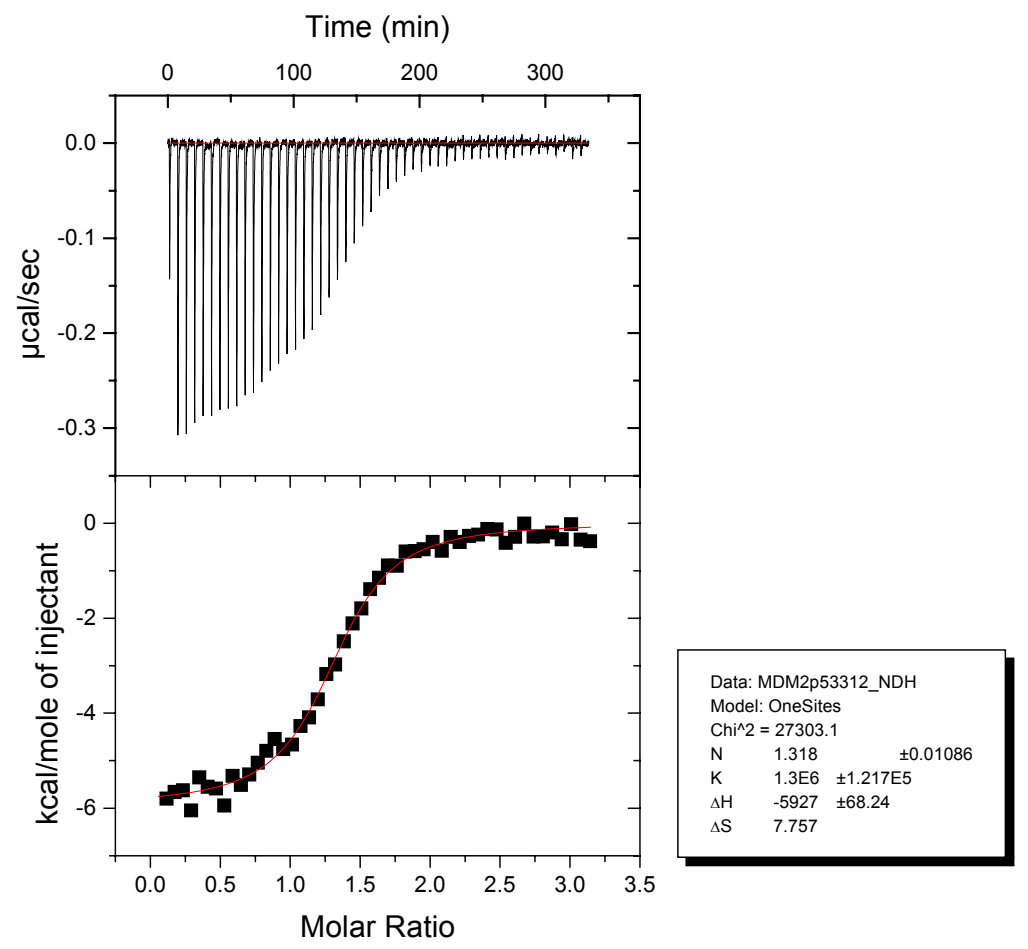




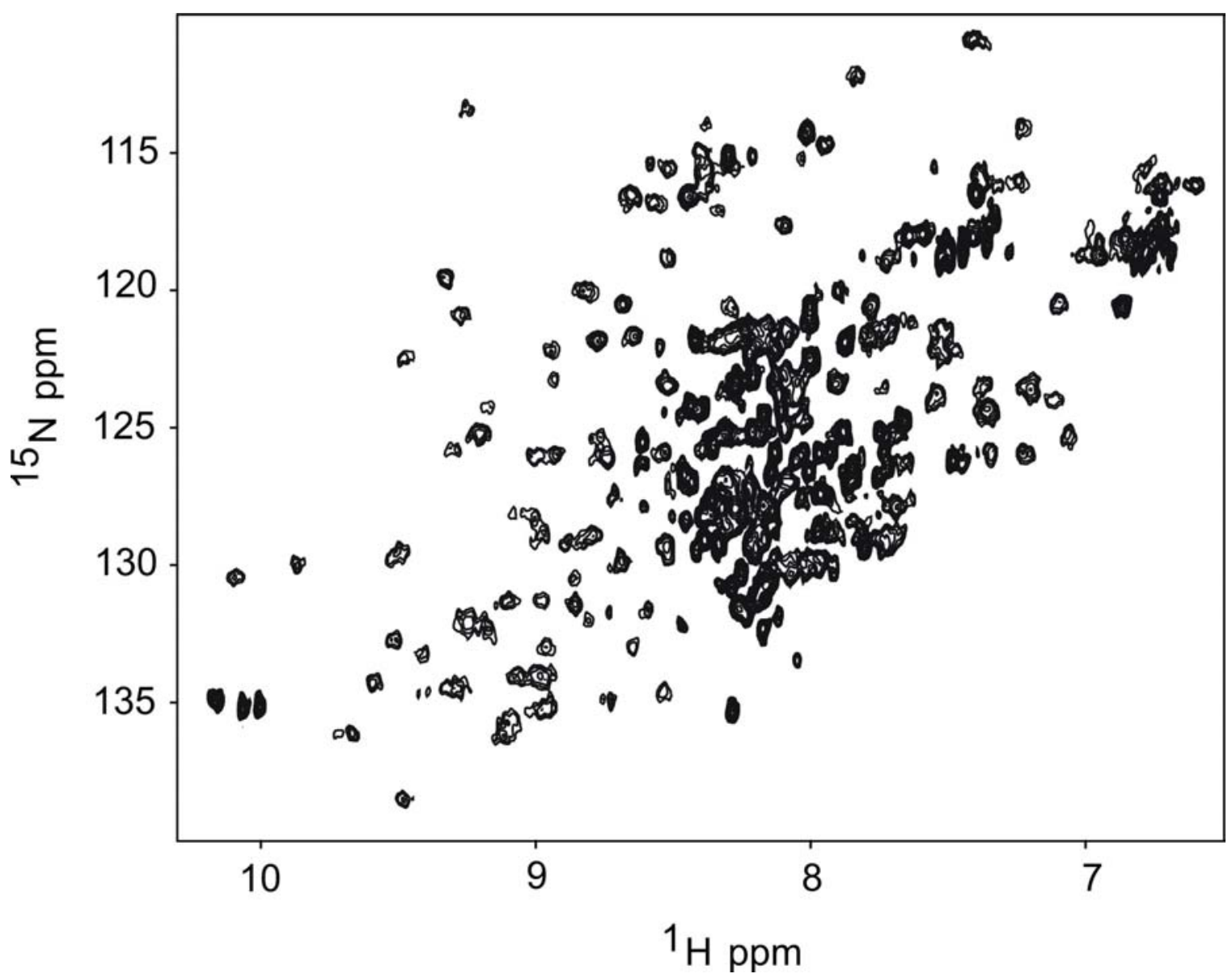

Supporting Figure 2. The spectrum of ${ }^{15} \mathrm{~N}$ p53 showing the structured regions of the protein. On release of p53 from the complex with MDM2, p53 retains its native form as seen by the HSQC spectrum taken after the dissociation of the complex. The resonances arising from structured parts of p53 are seen in the region between $8.5 \mathrm{ppm}$ and $10 \mathrm{ppm}$. 


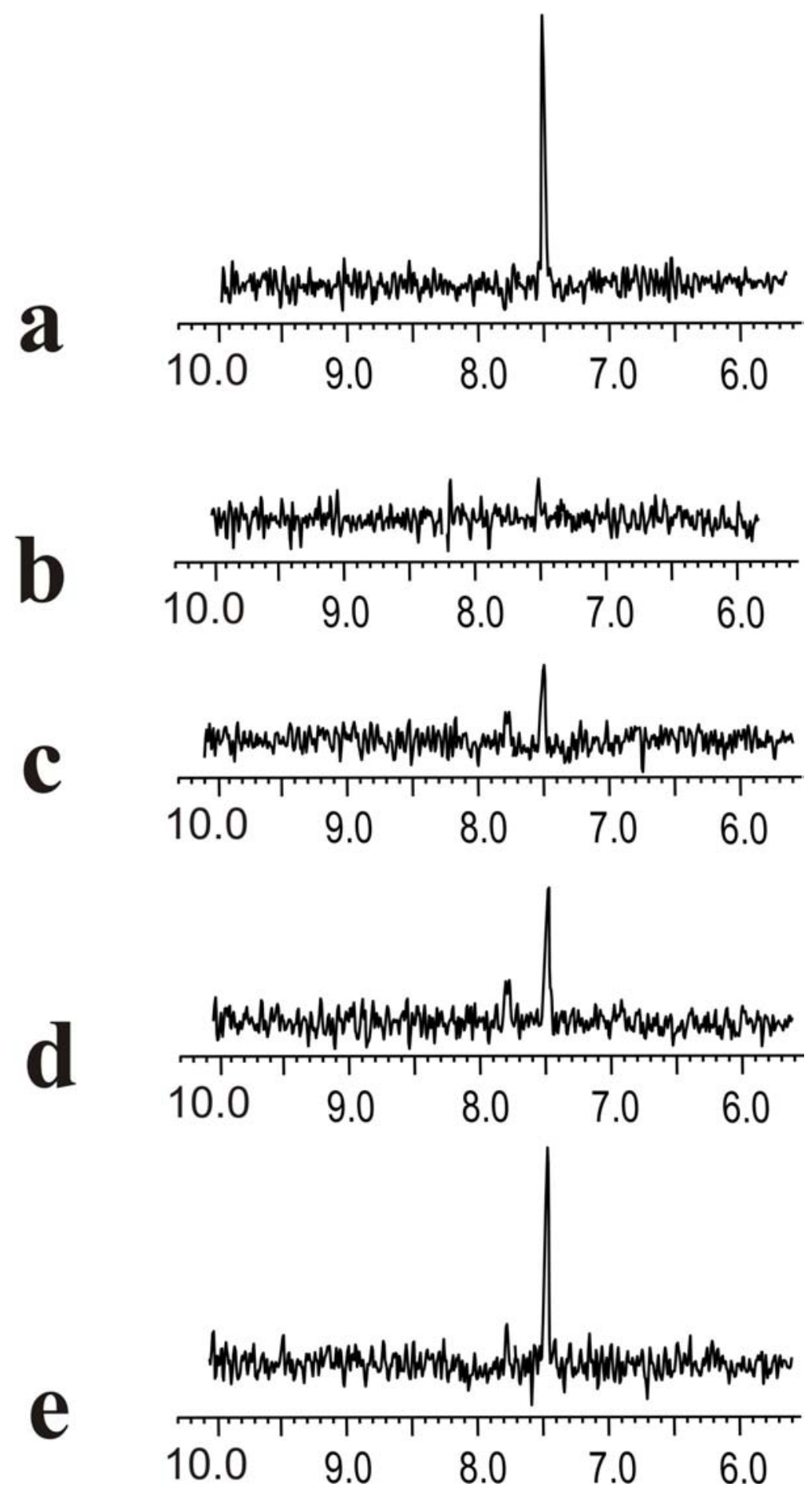

Supporting Figure 3. Cross sections of one of the residues from the ${ }^{1} \mathrm{H}^{-15} \mathrm{~N}$ HSQC spectra. (a) Free MDM2. (b) complex of MDM2 and p53. On additions of nutlin-3, the ratio of the complex to nutlin-3 is (c) 4:1, (d) 2:1 and (e) 1:1. 


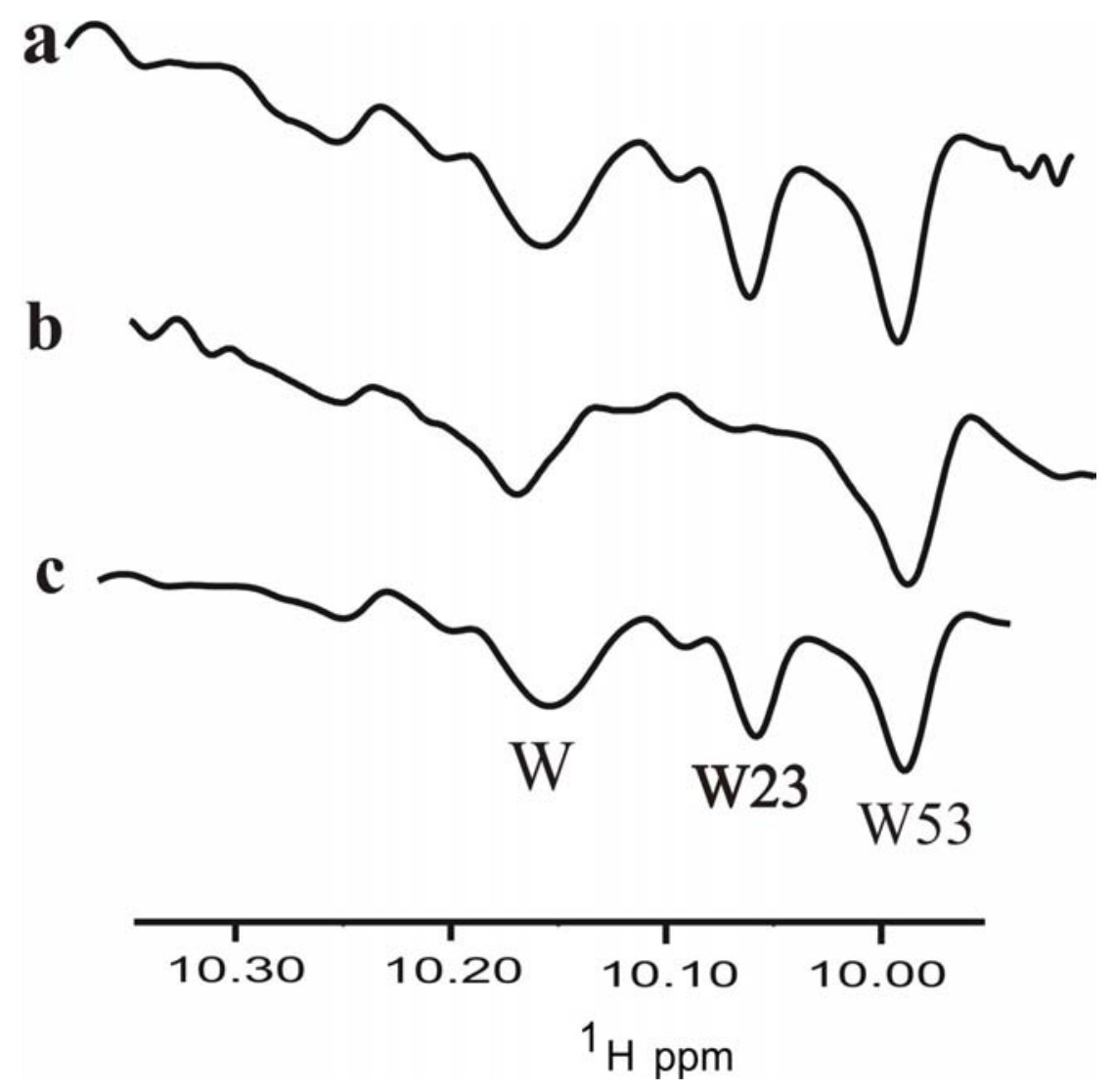

Supporting Figure 4. 1D proton spectra of the side chains of tryptophans (W) (for assignment refer $\mathrm{to}^{36}$ ). (a) Side chain peaks of free p53, showing W23, W53. W is the side chain peak from the tryptophan of the DNA binding region that is not assigned. (b) On forming a complex with MDM2, the side chain of Trp23 disappears (as in Figure 3b). The W53 peaks broaden as seen in the 2D spectrum also. (c) The peak reappears on addition of the sulfonamide, indicating that p53 has been released. 


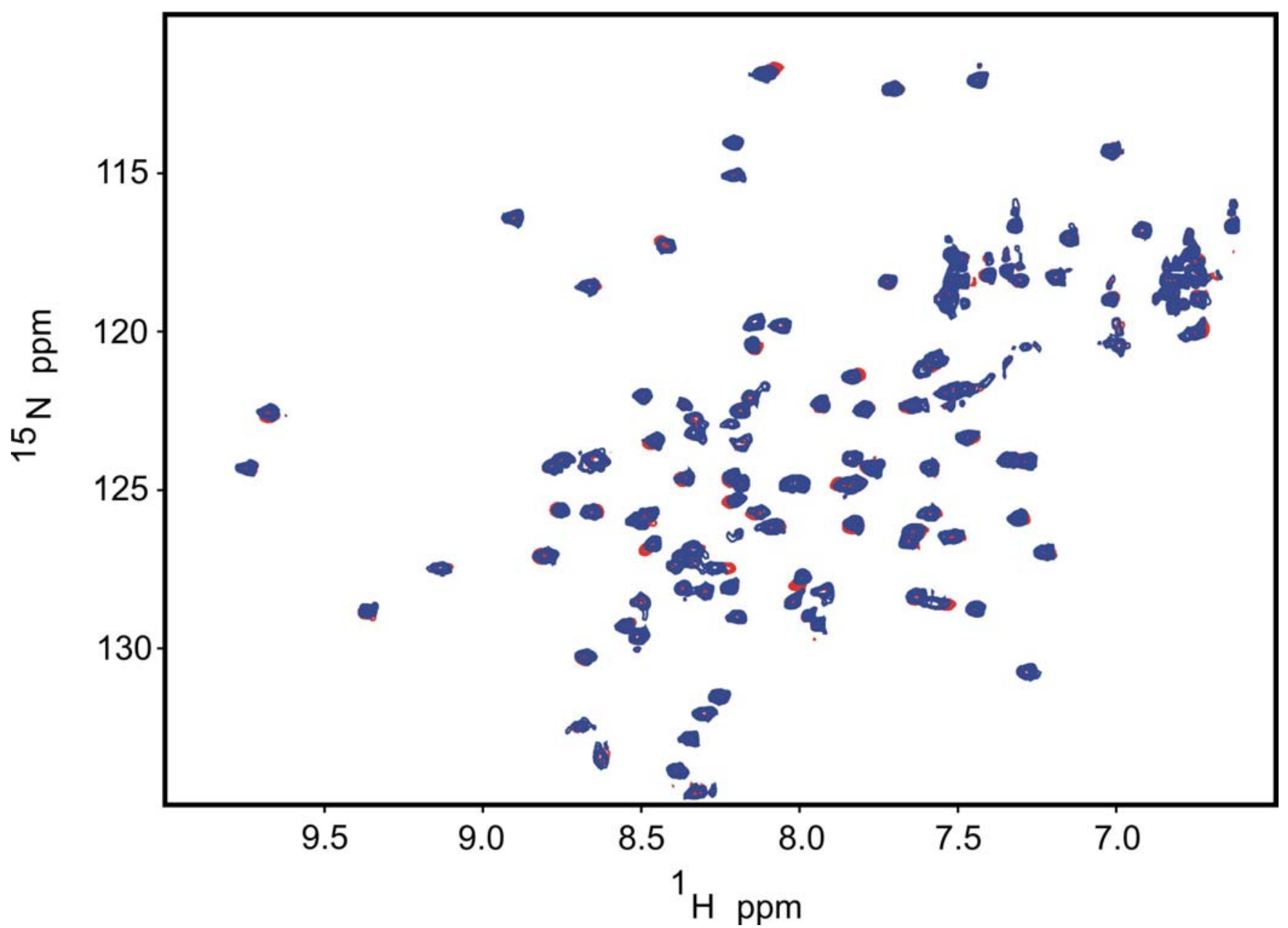

Supporting Figure 5. ${ }^{15} \mathrm{~N}$ HSQC spectra of MDM2, titrated with the sulfonamide. The reference spectrum is shown in red and the final spectrum after titration with sulfonamide is shown in blue at a ratio of $1: 1$. 


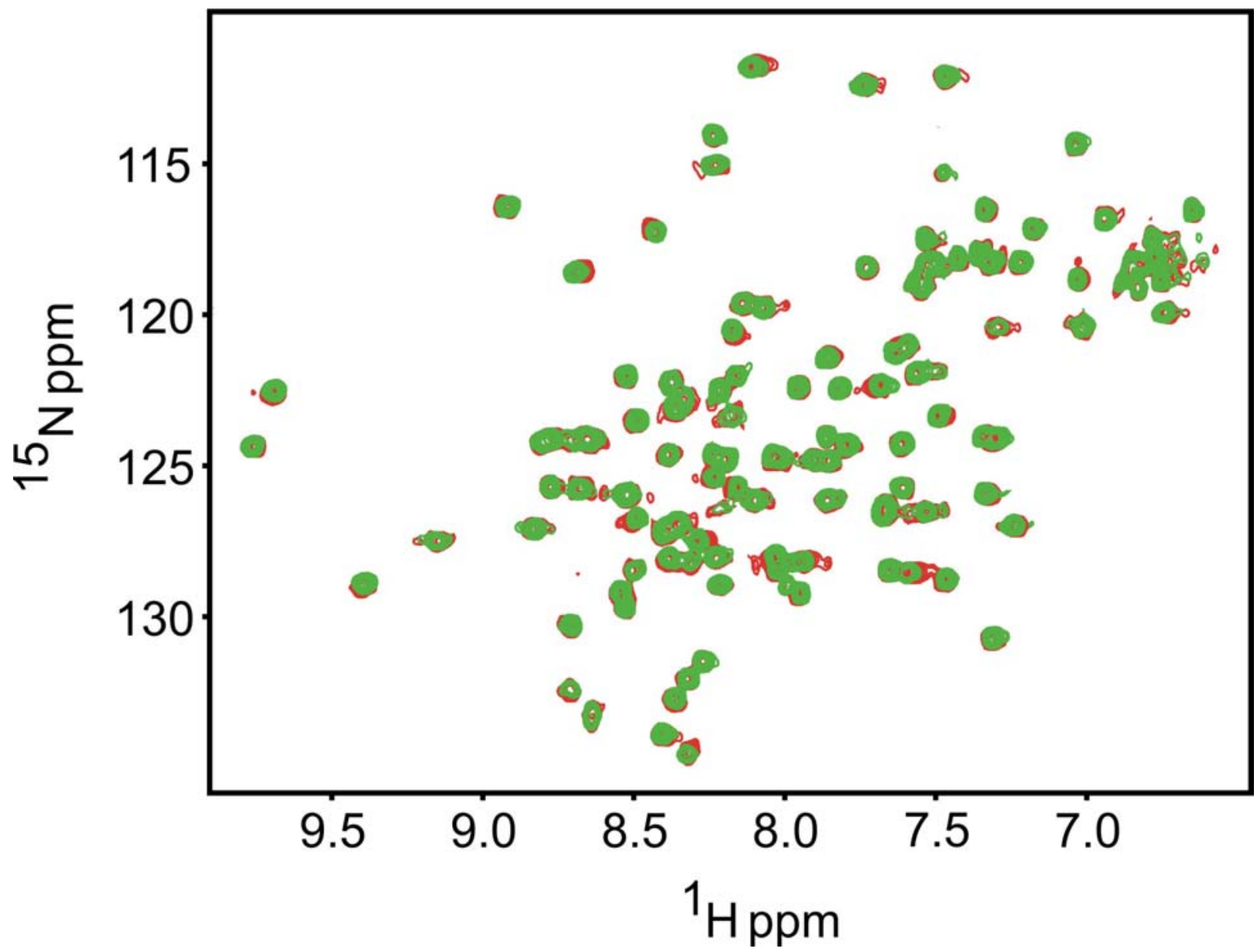

Supporting Figure 6. ${ }^{1} \mathrm{H}^{-15} \mathrm{~N}$ HSQC spectra of MDM2 (in red) titrated with DMSO (in green). There were no significant chemical changes when DSMO is added upto about $5 \%$ in the NMR tube containing the protein sample. DMSO at this amount did not induce precipitation/denaturation of the protein as seen from the $2 \mathrm{D}$ spectra. 


\section{Complete reference 23}

Bruce L. Grasberger, Tianbao Lu, Carsten Schubert, Daniel J. Parks, Theodore E. Carver, Holly K. Koblish, Maxwell D. Cummings, Louis V. LaFrance, Karen L. Milkiewicz, Raul R. Calvo, Diane Maguire, Jennifer Lattanze, Carol F. Franks, Shuyuan Zhao, Kannan Ramachandren, Gwendolyn R. Bylebyl, Marie Zhang, Carl L. Manthey, Eugene C. Petrella, Michael W. Pantoliano, Ingrid C. Deckman, John C. Spurlino, Anna C. Maroney, Bruce E. Tomczuk, Christopher J. Molloy, and Roger F. Bone. J. Med. Chem. 2005, 48, 909

\section{Complete reference 29}

Raphael Stoll, Christian Renner, Silke Hansen, Stefan Palme, Christian Klein, Anja Belling, Wojciech Zeslawski, Mariusz Kamionka, Till Rehm, Peter Mühlhahn, Ralf Schumacher, Friederike Hesse, Brigitte Kaluza, Wolfgang Voelter, Richard A. Engh, and Tad A. Holak. Biochemistry 2001, 40, 336. 